wird. Dass sie rasch näherrücke, dazu wird am meisten der Unterricht in darstellender Geometrie beitragen, der bereits an vielen Universitäton eingeführt ist und von den meisten angestrebt wird.

E.

Lehrbuch der Differentialgleichungen von $\mathrm{H}$. L i e bma $\mathbf{n} \mathbf{n}$. Mit zahlreichen Figuren im Text. Veit \& Comp., Leipzig, 1901.

Der Titel des Buches ist nicht ganz passend gewählt, denn in einem Lehrbuche der Differentialgleichungen erwartet man die systematische Darstellung der Theorie in ihrer ganzen Ausdehnung oder doch wenigstens die Grundzüge derselben zu finden. Keines von beiden bietet aber das Buch, sondern nur Bruchstücke aus dieser Theorie, die in bald mehr, bald minder eingehender Weise besprochen werden. So enthält das erste Capitel die Existenzbeweise, das zweite Betrachtungen über die gewöhnlichen Differentialgleichungen erster Ordnang, das dritte über Differentialgleichungen höherer Ordnung and Systeme gewöhnlicher Differentialgleichungen, die beiden letzten Erörterungen über partielle Differentialgleichungen der beiden ersten Ordnungen mit zwei unabhängigen Veränderlichen. Die Entwicklungen des ersten Capitels bewegen sich auf dem Boden der Functionentheorie; in den äbrigen werden die Lie'schen Begriffe von Linien-, Flächen-, Krümmungs-Element und Verein, die Berührungstransformation etc. herangezogen, die sehr geeignet sind, den Leser in die Auffassungsweisen Lies einzuführen.

Es verfolgt somit allem Anscheine nach der Verfasser mit seinem Buche die Absicht, die Functionentheorie and die Conceptionen Lie's, die bisher in getrennten Sphären sich entwickelten, in engere Verbindung mit einander zu setzen und Lie's Methoden auf die feste Basis der Functionentheorie zu stellen. Diesem Streben, das bald allgemeiner und mächtiger hervortreten dürfte, gebürt gewiss größtes Interesse und somit anch dem Buche als dem ersten, bescheidenen Versuche in dieser Richtung.

E.

\title{
Die Mathematik an den deutschen technischen Hochschulen
} von Papperitz. Beitrag zur Beurtheilung einer schwebenden Frage des höheren Unterrichtswesens. Veit \& Comp., Leiqzig, 1899.

Die kleine Schrift gieng aus einem Vortrage des Verfassers im bergmännischen Vereine zu Freiberg hervor, in dem er über die Frage der Ingenieurausbildung referierte. Er nimmt darin in lebhafter und entschiedener Weise Stellung gegen jede Verkürzung des mathematischen Unterrichtes, dem auch der in darstellender Geometrie beizuzählen ist, an den technischen Hochschulen und sucht in eindringlichen Worten die Vortheile einer tüchtigen mathematischen Schulung für den Techniker darzulegen. Man merkt es jedem Satze an, dass er aus der innersten Überzeugung des Verfassers quillt, aber nur der Unerfahrene vermöchte zu glauben, dass der heilige Eifer des Verfassers die starre Überzeugung auch nur eines seiner Gegner erschüttern wird.

Der Bewegung nach Einschränkung des rein theoretischen Unterrichtes an den technischen Hochschulen gieng roran eine parallele an den medicinischen Fakultäten nach Einschränkang des rein naturhistorischen Unterrichtes. Beide entspringen nahezu denselben Ursachen, sollten sie da einen verschiedenen Verlauf nehmen?

$E$. 